ISSN 0103-8478

\title{
Desenvolvimento de material de referência para microbiologia de alimentos contendo Listeria monocytogenes em matriz queijo
}

\author{
Development of reference material for food microbiology \\ containing Listeria monocytogenes in matrix
}

\author{
Marcelo Luiz Lima Brandão ${ }^{I^{*}}$ Juliana de Castro Beltrão da Costa ${ }^{\mathrm{I}}$ Felipe Miceli de Farias ${ }^{\mathrm{I}}$

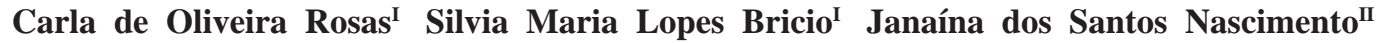 \\ Paola Cardarelli-Leite ${ }^{\mathrm{I}}$
}

\section{RESUMO}

A NBR ISO/IEC 17025:2005, uma das normas mais utilizadas em laboratórios de ensaio, descreve como um de seus critérios para a garantia da qualidade dos resultados analíticos a participação periódica dos laboratórios em ensaios de proficiência (EP). Os analitos, utilizados nos EP são materiais de referência (MR) provenientes de um mesmo lote, e devem apresentar caracteristicas de homogeneidade e estabilidade. O objetivo deste estudo foi produzir um MR qualitativo destinado ao ensaio de pesquisa de Listeria monocytogenes em matriz queijo pela técnica de liofilização. Para a produção do MR, foi utilizado como matriz o queijo Minas frescal (OMF) ultrafiltrado. A matriz foi distribuida em frascos, contaminada com a bactéria alvo e submetida à liofilização, tendo a sacarose como crioprotetor. O MR produzido foi considerado homogêneo e estável na temperatura de $\leq-70^{\circ} \mathrm{C}$ durante todo o periodo estudado (10 meses). O material apresentou estabilidade a $4,25,30$ e $35^{\circ} \mathrm{C}$ por quatro dias e a $-20^{\circ} \mathrm{C}$ por 48 dias, e os resultados estatísticos indicam tendência à estabilidade. Conclui-se que o material apresentou todos os requisitos necessários de um MR de qualidade e poderia ser transportado aos laboratórios participantes de um EP à temperatura máxima de $35^{\circ} \mathrm{C}$ por até quatro dias, uma vez que os resultados indicaram a manutenção da concentração celular nesse período. Esse foi o primeiro trabalho a descrever uma metodologia de produção de $M R$ contendo L. monocytogenes em matriz queijo.

Palavras-chave: material de referência, queijo, Listeria monocytogenes.

\section{ABSTRACT}

The standard most used in testing laboratories, ISO/ IEC 17025:2005, describes the participation of laboratories in periodic proficiency testing (PT), as a criteria for quality assurance of analytical results. The analyses used in PT are reference materials (MR) from the same lot, and must have characteristics of homogeneity and stability. This study aimed to produce a qualitative RM for detection of Listeria monocytogenes assays in cheese matrix. For the production of RM, Minas Frescal cheese (MFQ) was used as matrix. The matrix was distributed in flasks, contaminated with the target bacteria and submitted to freezedrying. Sucrose was used as cryoprotector. The RM produced was considered homogeneous and stable at $\leq-70^{\circ} \mathrm{C}$ during the entire period of study (10 months). The material showed stability at $4,25,30$ and $35^{\circ} \mathrm{C}$ for 4 days and at $-20^{\circ} \mathrm{C}$ the $R M$ showed stability for 48 days, and the statistical results indicate a tendency to maintain stability. It was concluded that the material showed all the requirements of an RM quality and could be transported to the laboratory participants of a PT at $35^{\circ} \mathrm{C}$ up to 4 days, since the results indicate the maintenance of cell concentration during this period. This is the first study to describe a methodology for producing MR containing $L$. monocytogenes in cheese matrix.

Key words: reference material, cheese, Listeria monocytogenes.

\section{INTRODUÇÃO}

A NBR ISO/IEC 17025:2005 tem sido reconhecida como uma das normas mais utilizadas em laboratórios de ensaio que buscam a garantia da qualidade analítica. Essa norma tem como um dos seus critérios a participação periódica em ensaios de proficiência (EP). A logística de um EP consiste no envio simultâneo de itens de ensaio com conteúdos desconhecidos aos laboratórios participantes, específicos para um tipo de ensaio. Os itens de ensaio são materiais de referência (MR) provenientes de um mesmo lote, que são suficientemente homogêneos (ABNT, 1999).

\footnotetext{
'Departamento de Microbiologia, Instituto Nacional de Controle de Qualidade em Saúde (INCQS), Fundação Oswaldo Cruz (Fiocruz), Av. Brasil, 4365, 21040-900, Manguinhos, Rio de Janeiro, RJ, Brasil. E-mail: marcelo.brandao@fiocruz.br. *Autor para correspondência. "Departamento de Microbiologia, Instituto Federal de Ciência, Educação e Tecnologia do Rio de Janeiro (IFRJ), Rio de Janeiro, RJ, Brasil. Recebido 07.01.13 Aprovado 23.05.13 Devolvido pelo autor 29.07.13 CR-2013-0012.R1
} 
Um MR é definido como "material ou substância com um ou mais valores de propriedades suficientemente homogêneos e bem estabelecidos" (ABNT, 2004). Quando preparados para utilização em $\mathrm{EP}$, os lotes de MR devem apresentar características de estabilidade, garantindo a distribuição de unidades com propriedades semelhantes, próximas a um valor padrão (THOMPSON et al., 2006).

A produção de MR para ensaios microbiológicos é dificultada pela sensibilidade das células bacterianas às variações de temperatura e ao processo de dessecação (PHILIPP et al., 2007). Atualmente, são escassas as informações sobre o preparo de MR, pois os provedores que comercializam MR para EP não divulgam o método de preparo dos materiais por eles produzidos. A maioria dos relatos sobre o preparo de MR destinado a ensaios microbiológicos em alimentos utiliza o leite como matriz, devido a sua propriedade de crioprotetor (IN'T VELD et al., 1995; ROSAS et al., 2010; INCQS, 2012a,b).

Os MR destinados a ensaios microbiológicos em alimentos podem ser qualitativos ou quantitativos. Os MR qualitativos são utilizados para verificar se a bactéria alvo está presente ou não no alimento, independente da concentração, como é o caso de determinados patógenos como Salmonella e Listeria monocytogenes (PHILIPP et al., 2007).

A legislação brasileira que estabelece os Padrões Microbiológicos para Alimentos tem como um dos parâmetros da avaliação da qualidade de queijos a ausência de L. monocytogenes (BRASIL, 2001). O queijo Minas frescal (QMF) é um dos produtos lácteos mais populares e consumidos no Brasil, sendo produzido em larga escala. Por ser alimento de pronto consumo, e indicado para idosos, gestantes e convalescentes, a sua inocuidade é de suma importância para que estes não venham a causar riscos à saúde do consumidor (VISOTTO et al., 2011).

L. monocytogenes já foi isolada de amostras de QMF em diferentes regiões do Brasil, o que demonstra a necessidade de um controle de qualidade mais rígido nesse tipo de alimento (VASCONCELOS \& MARIN, 2008).

Tendo em vista a carência de metodologias para produção de MR e a importância da pesquisa de L. monocytogenes em alimentos, o objetivo deste estudo foi desenvolver um MR qualitativo destinado à pesquisa de L. monocytogenes em matriz queijo.

\section{MATERIAL E MÉTODOS}

Seleção e preparação da matriz queijo

Uma amostra de QMF ultrafiltrado, obtida no comércio local foi utilizada como matriz. Essa amostra foi analisada para a verificação da ausência de contaminação por L. monocytogenes, segundo HITCHINS \& JINNEMAN (2011), e submetida à quantificação do número total de aeróbios viáveis de acordo com MATURIN \& PEELER (2001). A matriz de QMF foi distribuída em frascos de vidro estéreis com capacidade de $10 \mathrm{~mL}\left(2 \mathrm{~g}\right.$ frasco $\left.{ }^{-1}\right)$, completando um total de 216 frascos. Rolhas de borracha estéreis para liofilização foram posicionadas nos frascos e estes foram mantidos a $\leq-70^{\circ} \mathrm{C}$ por $24 \mathrm{~h}$. Os frascos foram liofilizados em aparelho liofilizador (K105, Liotop, Brasil) por $24 \mathrm{~h}$.

Produção do material de referência contendo $\boldsymbol{L}$. monocytogenes (MR-LM01)

Uma cepa de L. monocytogenes sorovar $1 / 2 \mathrm{a}$, isolada a partir de uma amostra de carcaça de frango e identificada pelo Laboratório de Zoonoses Bacterianas do Instituto Oswaldo Cruz/Fiocruz foi utilizada para produção do MR. Esse sorovar foi selecionado por ser o mais prevalente em amostras de alimentos (HITCHINS \& JINNEMAN, 2011). O micro-organismo foi cultivado em caldo tripticaseína de soja, contendo $0,6 \%$ de extrato de levedura (Difco, EUA) a $35^{\circ} \mathrm{C}$ por $24 \mathrm{~h}$. A cultura foi centrifugada a 9.000g por 10min (Eppendorf, EUA) e o sedimento ressuspenso em solução salina peptonada(SSP) a $0,1 \%$. A concentração de células foi ajustada em aparelho fotocolorímetro (Libra S2, Biochrom, Inglaterra) em $520 \mathrm{~nm}$, até uma transmitância de $6 \%\left(9 \times 10^{8}\right.$ células $\mathrm{mL}^{-1}$ ), e diluída em SSP a $0,1 \%$, contendo $100 \mathrm{mM}$ de sacarose $\left(\mathrm{C}_{12} \mathrm{H}_{22} \mathrm{O}_{11}\right)$ até atingir uma concentração de $9 \times 10^{3}$ células $\mathrm{mL}^{-1}$. A sacarose foi selecionada entre os diferentes aditivos crioprotetores por ser o glicídio mais frequentemente utilizado na criopreservação de bactérias (HUBÁLEK, 2003). Essa solução foi homogeneizada e volumes de $0,5 \mathrm{~mL}$ foram utilizados para contaminação dos frascos contendo a matriz de queijo liofilizada. Os frascos foram congelados e submetidos novamente a um ciclo de liofilização por $24 \mathrm{~h}$.

\section{Verificação de vácuo}

Após a liofilização, foi realizada a verificação do vácuo, conforme descrito por ROSAS et al. (2010). Os frascos que não apresentaram vácuo foram descartados e os demais foram lacrados com tampa metálica, identificados e estocados $\mathrm{a} \leq-70^{\circ} \mathrm{C}$. 
Avaliação da homogeneidade

Dez frascos, selecionados aleatoriamente, foram enumerados em duplicata e analisados segundo o método descrito por IN'T VELD et al. (1995), com modificações. Os frascos selecionados foram reconstituídos com $2 \mathrm{~mL}$ de SSP a 0,1\%. Após $15 \mathrm{~min}$, a matriz foi transferida para um saco plástico estéril com filtro (Nasco, EUA), seguido da adição de $16 \mathrm{~mL}$ de SSP a 0,1\% para atingir a proporção 1:10. O saco foi homogeneizado em aparelho Stomacher ${ }^{\circledR}$ (Seward Fisher Scientific, Canadá) durante 1 min. Alíquotas de $2 \mathrm{~mL}$ foram semeadas, em duplicata, pela técnica pour-plate, em $10 \mathrm{~mL}$ de ágar tripticaseína de soja, contendo 0,6\% de extrato de levedura (Difco, EUA), e as placas incubadas a $30^{\circ} \mathrm{C}$ por $4 \mathrm{~h}$. Após esse período, adicionou-se uma sobrecamada de $10 \mathrm{~mL}$ de ágar OXFORD (Oxoid, Inglaterra), contendo os agentes seletivos (SR0206E - Oxoid, Inglaterra), e as placas foram novamente incubadas a $30^{\circ} \mathrm{C}$ por mais $44 \mathrm{~h}$. Posteriormente, realizou-se a contagem das colônias negras presentes nas placas.

Avaliação da estabilidade

A avaliação da estabilidade foi realizada através de um estudo em longa e curta duração. O estudo em longa duração foi realizado na temperatura de referência $\left(\leq-70^{\circ} \mathrm{C}\right)$ e o em curta duração nas temperaturas que simulam o transporte do $\mathrm{MR}$ aos laboratórios a 4, 25, 30 e $35^{\circ} \mathrm{C}$; e na temperatura de estoque nos laboratórios após o recebimento do MR $\left(-20^{\circ} \mathrm{C}\right)$.

O estudo em longo prazo foi realizado segundo o modelo clássico (ISO, 2006), durante o período de 10 meses. Foram realizadas sete análises, de seis frascos, selecionados aleatoriamente, em intervalos de tempo determinados, utilizando a técnica descrita no estudo da homogeneidade.

O estudo em curta duração nas temperaturas de $4,25,30$ e $35^{\circ} \mathrm{C}$ foi realizado conforme o esquema descrito por ROSAS et al. (2010). Oito frascos do lote, estocados $\mathrm{a} \leq-70^{\circ} \mathrm{C}$, foram selecionados aleatoriamente e acondicionados em embalagens para transporte de material biológico (2 frascos embalagem $^{-1}$ ). A cada dia foram acrescentados dois frascos a cada uma das caixas incubadas nas temperaturas de $4,25,30$ e $35^{\circ} \mathrm{C}$, até um total de quatro dias. Após o quarto dia de incubação, todos os frascos utilizados mais dois frascos estocados $\mathrm{a} \leq-70^{\circ} \mathrm{C}$ (dia zero) foram enumerados conforme a técnica descrita na avaliação da homogeneidade.

O estudo em curta duração na temperatura de $-20^{\circ} \mathrm{C}$ foi realizado durante 48 dias, utilizando o modelo clássico (ISO, 2006). Quatorze frascos do lote produzido, selecionados aleatoriamente, foram acondicionados a $-20^{\circ} \mathrm{C}$ e, no mesmo dia, foi realizada a enumeração de dois frascos estocados $\mathrm{a} \leq-70^{\circ} \mathrm{C}$ (dia zero). A cada sete dias, dois frascos foram enumerados conforme a técnica descrita na avaliação da homogeneidade, até que os frascos acabassem.

\section{Avaliações estatísticas}

A homogeneidade do lote foi avaliada segundo THOMPSON et al. (2006). O valor de desvio-padrão alvo $\left(\sigma_{\mathrm{p}}\right)$ atribuído foi de $0,25 \log _{10}$ da concentração celular, conforme adotado por provedores de EP (INCQS, 2012a,b). A partir dos resultados obtidos, comparou-se o valor da variância entre as amostras $\left(\mathrm{S}^{2}{ }_{\mathrm{am}}\right)$ com o valor crítico da homogeneidade (c), em que o MR é considerado homogêneo quando $\mathrm{S}^{2}{ }_{\mathrm{am}}<\mathrm{c}$.

A avaliação dos resultados das contagens obtidos no estudo de estabilidade foi realizada pela análise de resíduos da regressão linear em conjunto com a análise da variância, segundo os critérios da ISO GUIDE 35 (ISO, 2006).

\section{RESULTADOS E DISCUSSÃO}

A amostra de QMF selecionada não apresentou contaminação por L. monocytogenes, sendo assim considerada uma matriz satisfatória para produção do MR. A contagem total de aeróbios viáveis foi de $1,2 \times 10^{3} \mathrm{UFC}^{-1}$. A presença da microbiota natural da amostra é importante para demonstrar a real capacidade do laboratório em enumerar e/ou pesquisar o(s) micro-organismo(s) alvo(s) (IN'T VELD et al., 1995).

A verificação do vácuo mostrou que 212 $(98,2 \%)$ frascos do lote produzido apresentaram vácuo. Esse resultado foi similar aos obtidos por outros autores que utilizaram a liofilização no preparo de MR e detectaram vácuo na maioria dos frascos dos lotes produzidos (ROSAS et al., 2010; VIEIRA et al., 2011).

Os resultados das contagens, em duplicata, do estudo de homogeneidade estão descritos na tabela 1. O lote apresentou os resultados de: 'c' $=0,016 \mathrm{e}$ $\mathrm{S}^{2}{ }_{\mathrm{am}}=0,00086$, sendo assim considerado homogêneo, segundo os critérios do protocolo harmonizado (THOMPSON et al., 2006).

O processo de liofilização já foi utilizado com sucesso na produção de MR homogêneos em matriz leite (INCQS, 2012a,b; ROSAS et al., 2010). $\mathrm{O}$ relato de estudos de produção em outros tipos de matrizes alimentícias é raro, devido às dificuldades na obtenção de materiais homogêneos e estáveis e do não 
Tabela 1 - Resultados das contagens dos itens de ensaio utilizados no estudo da homogeneidade, dados da análise de variância e avaliação, segundo o protocolo harmonizado.

\begin{tabular}{|c|c|c|c|c|c|}
\hline \multirow{2}{*}{ Frasco } & \multirow{2}{*}{\multicolumn{2}{|c|}{ Replicata 1}} & 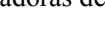 & & \multirow[b]{2}{*}{ Média } \\
\hline & & & Repli & & \\
\hline 1 & \multicolumn{2}{|c|}{2,239} & \multicolumn{2}{|c|}{2,156} & 2,198 \\
\hline 2 & \multicolumn{2}{|c|}{2,041} & \multicolumn{2}{|c|}{2,146} & 2,094 \\
\hline 3 & \multicolumn{2}{|c|}{2,079} & \multicolumn{2}{|c|}{2,156} & 2,118 \\
\hline 4 & \multicolumn{2}{|c|}{2,166} & \multicolumn{2}{|c|}{2,014} & 2,090 \\
\hline 5 & \multicolumn{2}{|c|}{2,028} & \multicolumn{2}{|c|}{2,000} & 2,014 \\
\hline 6 & \multicolumn{2}{|c|}{2,213} & \multicolumn{2}{|c|}{2,028} & 2,121 \\
\hline 7 & \multicolumn{2}{|c|}{2,204} & \multicolumn{2}{|c|}{2,091} & 2,148 \\
\hline 8 & \multicolumn{2}{|c|}{2,028} & \multicolumn{2}{|c|}{2,103} & 2,065 \\
\hline 9 & \multicolumn{2}{|c|}{2,230} & \multicolumn{2}{|c|}{2,166} & 2,198 \\
\hline 10 & \multicolumn{2}{|c|}{2,091} & \multicolumn{2}{|c|}{2,000} & 2,046 \\
\hline Média & $\sigma_{\mathrm{p}}$ & MQ & $\mathrm{S}_{\mathrm{am}}^{2}$ & Valor crítico 'c' & Resultado \\
\hline 2,109 & 0,25 & 0,0056 & 0,00086 & 0,016 & Suficientemente homogêneo \\
\hline
\end{tabular}

$\sigma_{\mathrm{p}}$ - desvio-padrão alvo; MQ- Médias quadráticas dentro dos grupos (fornecida pela Anova); $\mathrm{S}_{\mathrm{am}}^{2}$-Variância entre as amostras.

interesse dos produtores em divulgar suas técnicas de produção. VIEIRA et al. (2011) obtiveram MR homogêneos contendo Salmonella em matriz carne bovina crua, no entanto, ao utilizarem carne cozida e enlatada, relataram insuficiência de homogeneidade. Neste estudo, o processo desenvolvido obteve êxito na produção de um MR suficientemente homogêneo, contendo $\mathbf{L}$. monocytogenes na matriz queijo.

Os resultados do estudo de estabilidade estão descritos na tabela 2. A análise de regressão linear demonstrou que o MR foi considerado estável em todas as avaliações, pois os limites dos intervalos de confiança a 95\% abrangem o valor '0' (ISO, 2006). Os dados da literatura demonstram que os MR produzidos em matriz leite liofilizado são estáveis por períodos de até $\approx 237$ dias estocados $\mathrm{a} \leq-70^{\circ} \mathrm{C}$ (INCQS, 2012a,b). Resultados semelhantes foram obtidos neste estudo, pois o lote MR-LM01 apresentou-se estável durante 300 dias. No estudo da estabilidade de transporte, o lote MR-LM01 apresentou estabilidade por quatro dias à temperatura de até $35^{\circ} \mathrm{C}$. Esse resultado também é similar aos dos MR contendo bactérias mesófilas e B. cereus em matriz leite, que foram utilizados pelo INCQS em um EP e apresentaram-se estáveis nestas mesmas condições (INCQS, 2012a,b). Logo, o MR-LM01 poderia ser transportado aos laboratórios participantes de um EP a uma temperatura de até $35^{\circ} \mathrm{C}$ em um período máximo de quatro dias, uma vez que a avaliação estatística indicou a manutenção da concentração celular nessa condição. Como o transporte de materiais biológicos em temperatura de refrigeração é dispendioso, a obtenção de MR estáveis a temperaturas elevadas é importante para baratear o custo do envio dos itens de ensaio, consequentemente, diminuindo o custo total da participação do laboratório no EP.

Estudos demonstraram que os MR produzidos pela técnica de spray dryer foram estáveis por períodos de até dois anos a $-20^{\circ} \mathrm{C}$ (IN'T VELD et al., 1995). Com uso da técnica de liofilização, MR produzidos na matriz leite foram estáveis por períodos de até 38 dias (INCQS, 2012a,b). Contudo, ROSAS et al. (2010) produziram dois lotes de MR contendo Salmonella em leite, que foram estáveis por três meses, mas com tendência de decréscimo na concentração celular ao longo do tempo. Análises posteriores demonstraram que, após um ano, esses MR não se encontravam mais estáveis. O lote de MRLM01 apresentou estabilidade a $-20^{\circ} \mathrm{C}$ durante todo o período de estudo (48 dias) com baixo valor do coeficiente angular, indicando assim uma tendência à estabilidade. Contudo, um estudo mais prolongado deve ser realizado de forma a determinar o período máximo de estabilidade do MR quando estocado a $-20^{\circ} \mathrm{C}$.

De acordo com as bases de dados consultadas na literatura, o presente trabalho foi o primeiro a descrever uma metodologia para a produção de MR contendo L. monocytogenes em matriz queijo. O desenvolvimento de metodologias de produção de MR em diferentes matrizes e contendo as diversas classes de micro-organismos de interesse em Saúde Pública é importante para aumentar o escopo dos provedores de EP e, consequentemente, o aprimoramento da qualidade analítica dos laboratórios de microbiologia de alimentos. 
Tabela 2 - Resultados das médias das contagens do estudo de estabilidade.

\begin{tabular}{|c|c|c|c|c|c|c|}
\hline \multirow{2}{*}{ Tempo (dias) } & \multirow[b]{2}{*}{$\leq-70^{\circ} \mathrm{C}$} & \multicolumn{4}{|c|}{-- $\log _{10}$ Unidades Formadoras de Colônia de L. monocytogenes $\mathrm{g}^{-1}$} & \multirow[b]{2}{*}{$35^{\circ} \mathrm{C}$} \\
\hline & & $-20^{\circ} \mathrm{C}$ & $4^{\circ} \mathrm{C}$ & $25^{\circ} \mathrm{C}$ & $30^{\circ} \mathrm{C}$ & \\
\hline 0 & 2,116 & 1,973 & 1,870 & 1,870 & 1,870 & 1,870 \\
\hline 1 & $\mathrm{NR}^{\mathrm{a}}$ & NR & 1,927 & 2,065 & 2,097 & 1,792 \\
\hline 2 & NR & NR & 1,983 & 2,090 & 2,013 & 2,094 \\
\hline 3 & NR & NR & 1,903 & 1,678 & 1,999 & 1,620 \\
\hline 4 & NR & NR & 1,737 & 1,779 & 1,872 & 1,669 \\
\hline 7 & NR & 1,922 & NR & NR & NR & NR \\
\hline 14 & NR & 2,117 & NR & NR & NR & NR \\
\hline 21 & NR & 2,082 & NR & NR & NR & NR \\
\hline 28 & $\mathrm{NR}$ & 1,984 & NR & NR & NR & NR \\
\hline 30 & 1,481 & NR & NR & NR & NR & NR \\
\hline 35 & NR & 2,112 & NR & NR & NR & NR \\
\hline 48 & NR & 2,184 & NR & NR & NR & NR \\
\hline 63 & 1,899 & NR & NR & NR & NR & NR \\
\hline 86 & 1,838 & NR & NR & NR & NR & NR \\
\hline 124 & 1,920 & NR & NR & NR & NR & NR \\
\hline 140 & 1,950 & NR & NR & NR & NR & NR \\
\hline 258 & 1,887 & NR & NR & NR & NR & NR \\
\hline 300 & 1,977 & NR & NR & NR & NR & NR \\
\hline \multicolumn{7}{|l|}{ Regressão linear } \\
\hline Coeficiente angular & 0,00035 & 0,0043 & $-0,029$ & $-0,057$ & $-0,0094$ & $-0,057$ \\
\hline Limite inferior & $-0,0013$ & $-0,000018$ & $-0,12$ & $-0,24$ & $-0,12$ & $-0,25$ \\
\hline Limite superior & 0,0020 & 0,0085 & 0,063 & 0,12 & 0,10 & 0,13 \\
\hline Resultado & Estável & Estável & Estável & Estável & Estável & Estável \\
\hline
\end{tabular}

a - Não realizado.

\section{CONCLUSÃO}

O MR-LM01 apresentou todos os requisitos necessários de um MR de qualidade, sendo considerado homogêneo e estável. No futuro, esse MR poderá ser utilizado em um EP destinado ao ensaio de pesquisa de $\mathbf{L}$. monocytogenes em matriz queijo.

\section{REFERÊNCIAS}

ABNT (ASSOCIAÇÃO BRASILEIRA DE NORMAS TÉCNICAS). NBR ISO/GUIA 34: Requisitos gerais para a competência de produtores de materiais de referência. Rio de Janeiro, 2004. 25p.

ABNT (ASSOCIAÇÃO BRASILEIRA DE NORMAS TÉCNICAS). NBR ISO/IEC GUIA 43-1: Ensaios de proficiência por comparações interlaboratoriais - Parte 1 - Desenvolvimento e operação de programas de ensaios de proficiência. Rio de Janeiro, 1999. $17 \mathrm{p}$.

ABNT (ASSOCIAÇÃO BRASILEIRA DE NORMAS TÉCNICAS). NBR ISO/IEC 17025: Requisitos gerais para a competência de laboratórios de ensaio e calibração. Rio de Janeiro, 2005. 31p.
BRASIL. Ministério da Saúde. Agência Nacional de Vigilância Sanitária. Resolução RDC n ${ }^{\circ} 12$, de 02 de janeiro de 2001. Regulamento Técnico sobre Padrões Microbiológicos para Alimentos. Diário Oficial da União, Brasília, DF, 10 jan. 2001. Seção 1, p.45.

CARDOSO, M.H.W.M. et al. Preparação de um material de referência certificado para controle de agrotóxicos em hortifrutigranjeiros: estudo de estabilidade. Ciência e Tecnologia de Alimentos, v.30, n.2, p.439-446, 2010. Disponível em:<http:// www.scielo.br/pdf/cta/v30n2/21.pdf>. Acesso em: 7 ago. 2012.

HITCHINS, A.D.; JINNEMAN, K. Detection and enumeration of Listeria monocytogenes in Foods. In: Bacteriological analytical manual online. 8.ed. Revision A, 1988. USA: Food and Drug Administration, 2011. Cap.10, Capturado em: 7 ago. 2012. Online. Disponível em: <http://www.fda.gov/Food/ScienceResearch/ LaboratoryMethods/BacteriologicalAnalyticalManualBAM/ ucm071400.htm>.

HUBÁLEK, Z. Protectants used in the cryopreservation of microorganisms. Cryobiology, v.46, n.3, p.205-229, 2003. Disponível em: <http://dx.doi.org/10.1016/S0011-2240(03)000464>. Acesso em: 7 ago. 2012. doi: 10.1016/S0011-2240(03)00046-4.

IN'T VELD, P.H. et al. Potential use of microbiological reference materials for the evaluation of detection methods for Listeria monocytogenes and the effect of competitors; a collaborative 
study. Food Microbiology, v.12, p.125-134, 1995. Disponível em: <http://dx.doi.org/10.1016/S0740-0020(95)80088-3>. Acesso em: 7 ago. 2012. doi: 10.1016/S0740-0020(95)80088-3.

INCQS. Ensaio de Proficiência em Produtos Sujeitos ao Regime de Vigilância Sanitária. Ensaio de Proficiência em Microbiologia de Alimentos 3a Rodada Contagem de Bactérias Mesófilas Matriz Leite em Pó Rodada EP MIB03/11. Relatório final... Rio de Janeiro: INCQS/Fiocruz, 2012a. 22p. Capturado em: 7 ago. 2012. Online. Disponível em: <http://www.incqs.fiocruz.br/images/ stories/incqs/ensaio/2011/EP_MIB_03_11_Relatorio_Final.pdf>.

INCQS. Ensaio de Proficiência em Produtos Sujeitos ao Regime de Vigilância Sanitária. Ensaio de Proficiência em Microbiologia de Alimentos 4- Rodada Contagem de Bacillus cereus Matriz Leite em Pó Rodada EP MIB04/11. Relatório final... Rio de Janeiro: INCQS/Fiocruz, 2012b. 22p. Capturado em: 7 ago. 2012. Online. Disponível em: $<$ http://www.incqs.fiocruz.br/images/stories/incqs/ ensaio/2011/EP_MVT_04_11_Protocolo.pdf>. ORGANIZATION

FOR

STANDARDIZATION. ISO GUIDE 35: reference materialsGeneral and statistical principles for certification. Geneva, 2006. $62 \mathrm{p}$.

MATURIN, L.; PEELER, J.T. Aerobic plate count. In: Bacteriological analytical manual. 8.ed. Revision A, 1998. USA: Food and Drug Administration, 2001. Cap.3. Capturado em: 7 ago. 2012. Online. Disponível em: $<$ http:// www.fda.gov/Food/ScienceResearch/LaboratoryMethods/ BacteriologicalAnalyticalManualBAM/ucm063346.htm>.

PHILIPP, W.J. et al. Development of reference materials for microbiological analysis. Accreditation and Quality Assurance, v.12, n.3-4, p.134-138, 2007. Disponível em: <http://dx.doi. org/10.1007/s00769-006-0244-3>. Acesso em: 7 ago. 2012. doi: 10.1007/s00769-006-0244-3.
ROSAS, C.O. et al. Desenvolvimento de material de referência para ensaio de proficiência em microbiologia de alimentos. Revista do Instituto Adolfo Lutz, v.69, n.1, p.15-22, 2010. Disponível em: $<$ http://revista.ial.sp.gov.br/index.php?option $=$ com_remository\&I temid $=27 \&$ func $=$ showdown\&id=542>. Acesso em: 7 ago. 2012 .

THOMPSON, M. et al. International harmonized protocol for proficiency testing of (chemical) analytical chemistry laboratories. Pure and Applied Chemistry, v.78, n.1, p.145-196, 2006. Disponível em: <http://dx.doi.org/10.1351/pac200678010145>. Acesso em: 7 ago. 2012. doi: 10.1351/pac200678010145.

VASCONCELOS, R.M.; MARIN, V.A. Listeria monocytogenes em queijo minas frescal e critérios para a avaliação de risco. Segurança alimentar e nutricional, v.15, n.2, p.32-45, 2008. Disponível em: <http://www.unicamp.br/nepa/arquivo_san/3 09 artigo_1419_Listeria_Monocytogenes.pdf $>$. Acesso em: 7 ago. 2012 .

VIEIRA, L.R. et al. Desenvolvimento de metodologia para a produção de material de referência em matriz de carne bovina para detecção de Salmonella spp. In: ENCONTRO NACIONAL DE ANALISTAS DE ALIMENTOS, 17., e CONGRESSO LATINO AMERICANO DE ANALISTAS DE ALIMENTOS, 3., 2011, Cuiabá, MT. Anais... São Paulo: SBAAL, 2011. Disponível em: $<$ http://www.idacta.net/io/resumos/enaal2011/default. asp? action=aprovados\&busca.asp?tit=busca $>$. Acesso em: 7 ago. 2012.

VISOTTO, R.G. et al. Queijo minas frescal: perfil higiênicosanitário e avaliação da rotulagem. Revista do Instituto Adolfo Lutz, v.70, n.1, p.8-15, 2011. Disponível em: <http://revista.ial. sp.gov.br/index.php?option $=$ com_remository \&Itemid $=27 \&$ func $=\mathrm{f}$ ileinfo\&id $=640>$. Acesso em: 7 ago. 2012. 